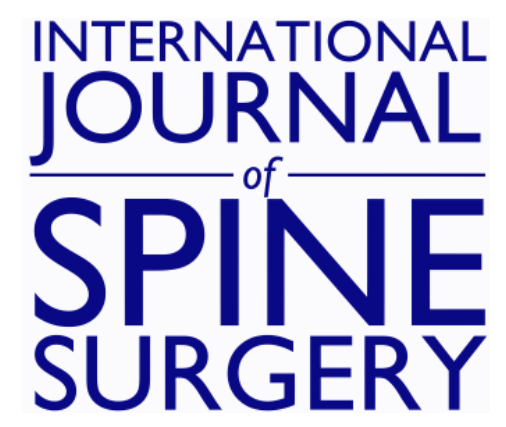

\title{
A case report of extramedullary haematopoeisis in lumbosacral region presenting as cauda equina syndrome
}

Shardul Soman, G D Tharadara, Naitik Chhatrala and Shubham Jain

Int J Spine Surg 2016, 10 ()

doi: https://doi.org/10.14444/3025

http://ijssurgery.com/content/10/25

This information is current as of April 26, 2023.

Email Alerts Receive free email-alerts when new articles cite this article. Sign up at:

http://ijssurgery.com/alerts

The International Journal of Shing Surgerih 2397 Waterbury Circle, Suite 1,

Aurora, IL 60504, Phone: +1-630-375-1432

(C) 2016 ISASS. All Rights Reserved. 


\section{A case report of extramedullary haematopoeisis in lumbosacral region presenting as cauda equina syndrome}

Shardul Soman, MS Ortho, DNB Ortho., ${ }^{1}$ G D Tharadara, MS Ortho., ${ }^{2}$ Naitik Chhatrala, ${ }^{2}$ Shubham Jain ${ }^{2}$

${ }^{1}$ Department of Spine, Government Spine Institute, Ahmedabad, India 2Department of Orthopaedics, B. J.Medical College and Civil Hospital Ahmedaba, India

\section{Abstract}

Introduction

Extramedullary hematopoeisis (EMH) is defined as formation of blood cells outside the bone marrow. It occurs most commonly in the liver and spleen in patients having disorders that lead to chronic anaemia. EMH in spinal canal is a very rare site and cauda equina syndrome due to EMH has very few cases presented in literature.

\section{Case Presentation}

A 28 year old male patient presented with complain of incontinenance of bladder and bowel along with saddle anaesthesia from 10 days. Patient was a known case of beta-thalassemia intermedia. And MRI scan of the spine showed multiple well circumscribed, enhancing lesions in the epidural space extending from L5 to S3 and resulting in compression of the cauda equina. Patient underwent posterior neural decompression by a laminectomy from L5 to S3. At 3 months follow up patient had partial recovery of his bladder control and complete recovery of sensation.

\section{Conclusion}

EMH should be recognized early on the basis of clinical features and MRI findings. The various modalities available for treatment of such cases includes blood transfusion, low dose radiotherapy, hydroxyurea and surgical decompression.

There are very few cases noted in the literature of such phenomenon in the lumbosacral spine. In cases of acute presentations like cauda equine surgical decompression is a treatment modality of choice.

KEYWORDS: EXTRAMEDULLARY, HEMATOPOIESIS, THALASSEMIA, COMPRESSION

VOLUME 10 ARTICLE 25 DOI: 10.14444/3025

\section{Introduction}

Extramedullary hematopoeisis( EMH) is a physiological compensatory phenomenon occurring in almost all chronic haemolytic anaemia cases and more particular in thalassemia. The most common sites involved includes the spleen, liver, lymph nodes, adrenal glands, pleura. ${ }^{1}$ EMH though rarely involves the spinal canal it can lead to compression and associated clinical presentation depending on the level of involvement. It was first described by Gatto et al. ${ }^{2}$ who described a 23 year old female having paraparesis due thoracic epidural space involvement.EMH predominates in males (male/female ratio of 5:1) and mostly involves the lower thoracic spine. ${ }^{3}$ Treatment options of this rare complication in controversial with blood transfusion, hydroxyurea, radiotherapy and surgical management.

\section{Case Presentation}

A 28 year old male patient presents with complain of incontinence of bladder and bowel along with saddle anaesthesia from 10 days. He had normal motor power in both lower limbs and on sensory examination showed hypoesthesia in the $\mathrm{S} 1$ to $\mathrm{S} 5$ dermatomes bilaterally. Other neurological findings were normal. There was no previous history of backpain or radicular pain involving the lower extremities. His urological examination revealed no evidence of any pathology of the kidneys of ureters. Clinical and biological tests showed no evidence of any infectious etiology. Patient was a known case of beta-thalassemia intermedia and had history of multiple previous blood transfusions. On systemic examination he had hepato-splenomegaly. His blood parameters were suggestive of chronic anaemia due to the underlying haematological condition. Patient had haemoglobin 
of $7 \mathrm{gm} \%$ with platelet count being $85000 / \mathrm{microL}$. And MRI scan of the spine showed multiple wellcircumscribed, enhancing lesions in the epidural space extending from L5 to S3 and resulting in compression of the cauda equina. The masses were hypointense on both $\mathrm{T} 1$ and T2 images (Figure 1, Figure 2). Patient underwent posterior decompression by a laminectomy extending from L5 lower lamina upto $\mathrm{S} 3$ upper lamina. Intra operatively the masses where reddish vascular lesions slightly adherent to the ventral dura (Figure 3, Figure 4). Also per operatively the biopsy of the enhancing masses was taken. On histopathological examination it was confirmed to be extramedullary hematopoeisis due to the erythroid hyperplasia (Figure 5).Postoperative course showed improvement in the saddle anaesthesia and the $\mathrm{S} 1$ dermatomal hypoesthesia. At the end of three months patient had partially regained his bladder control while showing complete improvement in his bowel control. Patient however continued to have increase in his spleen size for which he required frequent blood transfusion before his $\mathrm{Hb}$ stabilized at 9 gm\%, however splenectomy was not required as per advice by gastroenterology surgeon.

\section{Discussion}

Since the first report of EMH published in 1954 a recent retrospective analysis of the of radiological records of 44 patients with EMH revealed 12 patients (27\%) who had focal mass like lesions, ten of these had one or more masses in the axial skeleton. The thoracic spine and to a very lesser extent the lumbar spine were the most commonly involved sites ${ }^{4}$. Symptomatic spinal cord compression secondary to EMH shows a preference for localisation in the middle and lower thoracic spine. Some authors related this to the narrow spinal diameter spinal diameter at this level ${ }^{5}$.Here we present a patient with predominantly sacral canal involvement leading to compression.

The exact origin of the hematopoietic tissue is still unknown, Da Costa et al. ${ }^{6}$ hypothesized that it could arise directly by extrusion through the trabecular bone of the vertebral body or the rib heads. Among the diagnostic tools nuclear isotopic scans can show every ectopic fusion EMH but the gold standard as for any spinal pathology remains MRI. ${ }^{7}$ The principle MR imaging characteristics of EMH includes the following: an extramedullary mass (more often in the posterior location of the epidural space and in the thoracic region) with homogenous signal intensity on $\mathrm{T} 1$ weighted images and slightly higher intensity of signal than the adjacent red marrow of the vertebral bodies on $\mathrm{T} 2$ weighted images and enhancement after gadolinium injection. ${ }^{5,8}$ Differential diagnosis is often easy when the lesion is multifocal (paravertebral and epidural) or bilateral due to characteristics iron deposition or fatty replacement and characteristic topography. The only diagnostic problem exists with the solitary unilateral active lesion. Mesenchymal tissue tumors or those from neural tissue elements should be included in the differential diagnosis but the clinical history of congenital haemolytic should lead to correct diagnosis. ${ }^{9}$

Because of its rarity no evidence based guidelines for

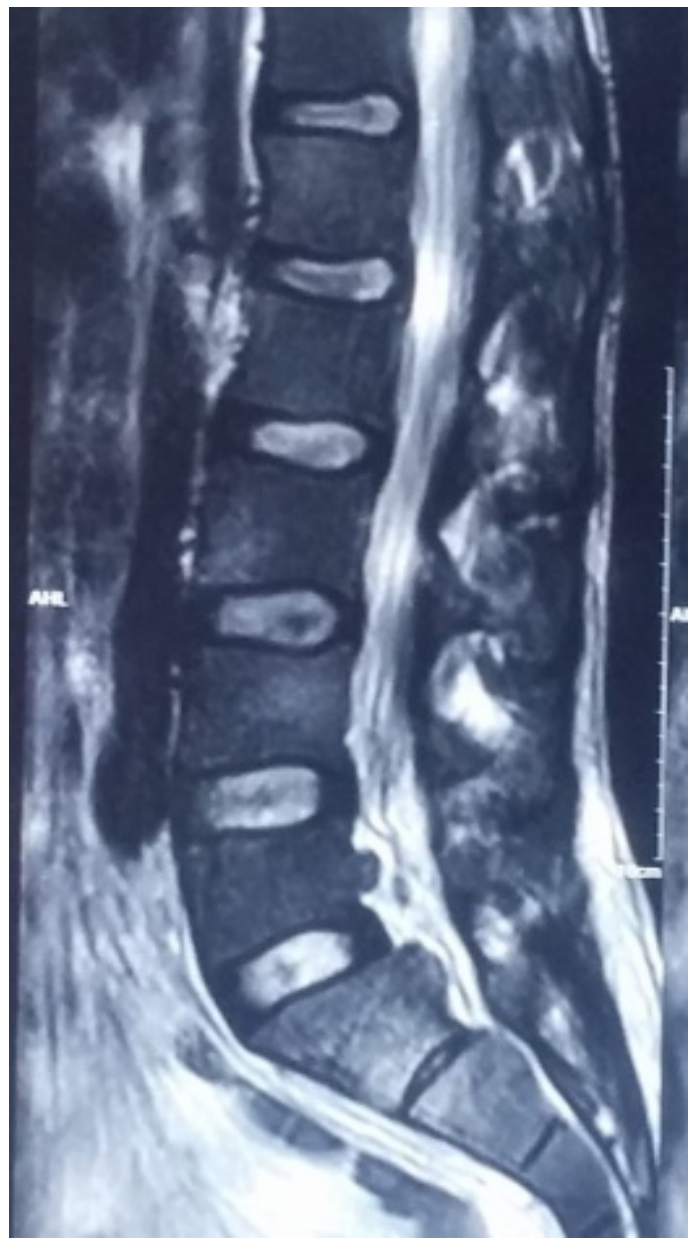

Fig. 1. MRI T2 image of the lumbar spine showing the extramedullary masses in the anterior epidural space at L5-S3. 
the treatment of paraspinal or guidelines for the treatment of paraspinal or epidural. EMH exist management options includes blood transfusion, radiotherapy, surgical decompression, hydroxyurea or a combination of these modalities. The treatment mostly depends upon the severity of symptoms, size of mass and clinical condition. In patients with transfusion independence blood transfusion can correct the anemia and indirectly reduce the need for $\mathrm{EMH}$, leading to its shrinkage and clinical improvement. However this therapy has its own complications associated with transfusion and the response is slow, temporary and insufficient. ${ }^{10}$

Low dose radiation has been reported to yield excel-

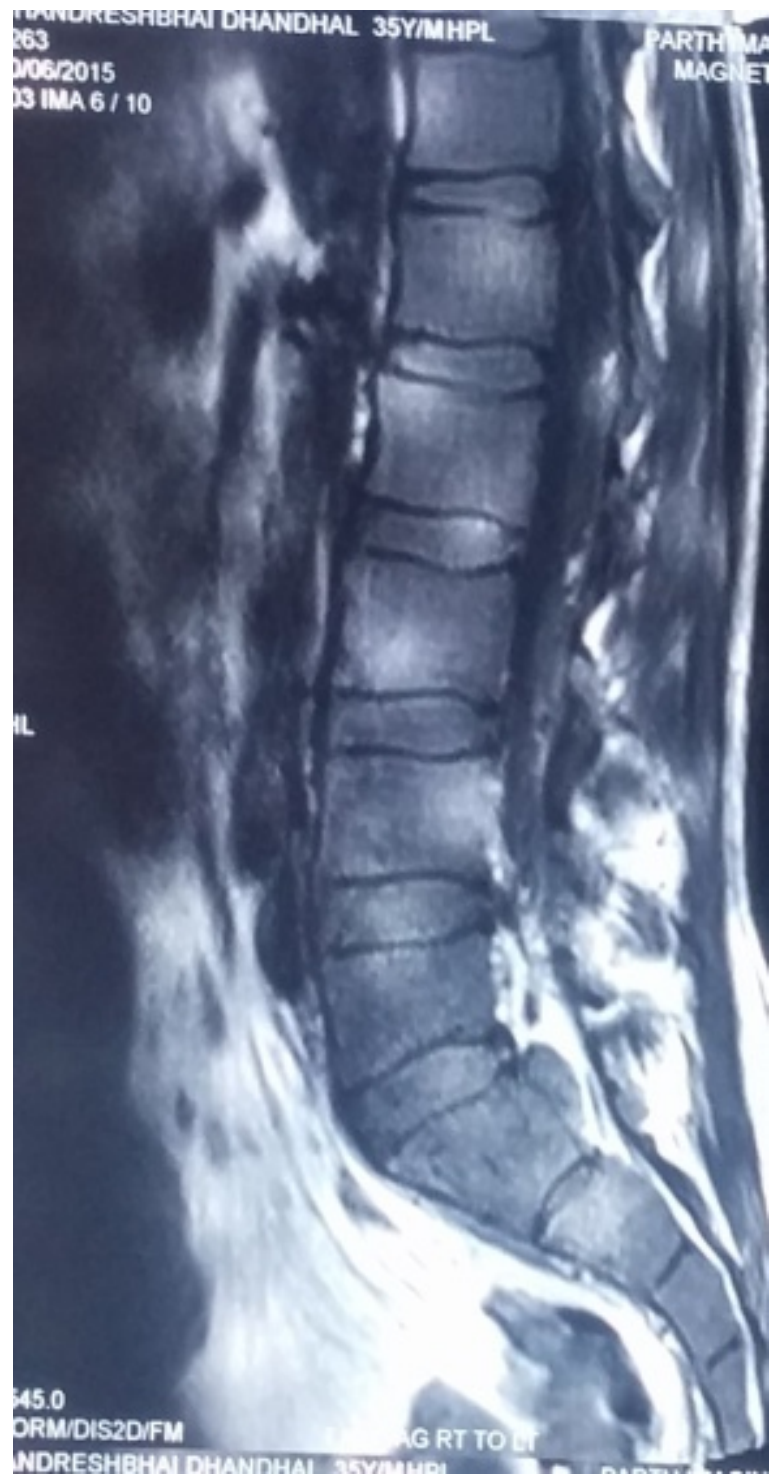

Fig. 2. MRI T1 weighted image showing the hypointense extramedullary masses most prominent behind the $\mathrm{S} 1$. lent result in upto $50 \%$ of patients, with neurological

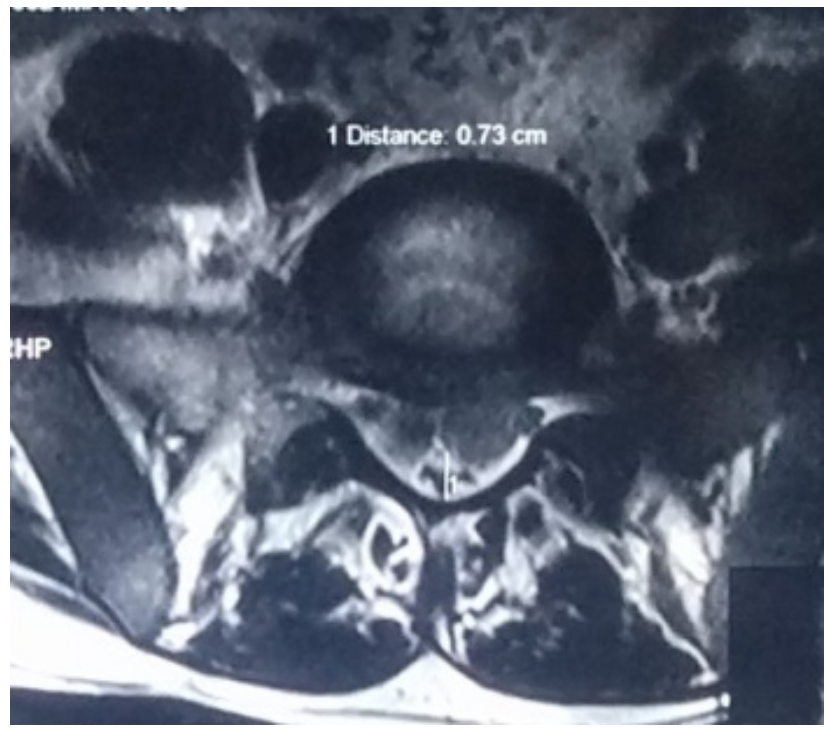

Fig. 3. Axial T2 weighted MRI at the level of S1 showing the anterior epidural space encroached by the extramedullary masses leading to compression.

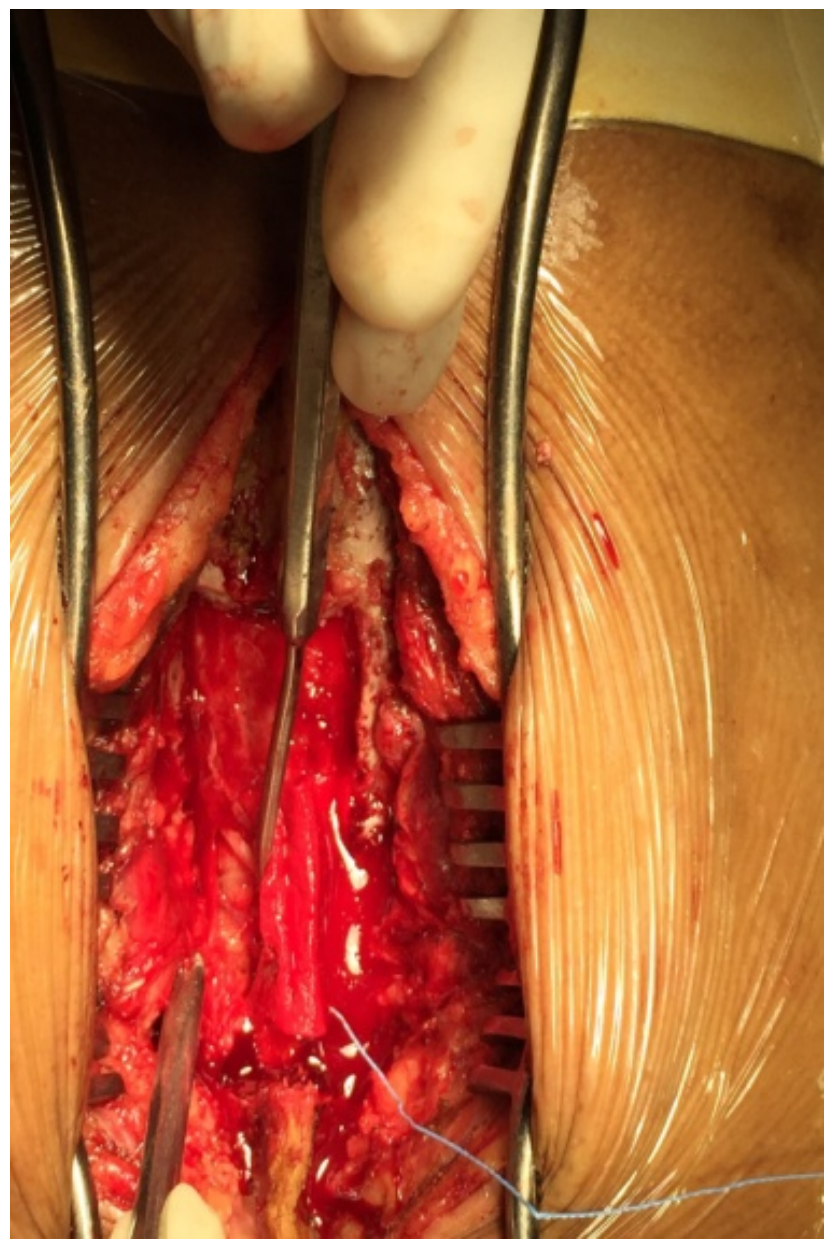

Fig. 4. Per operative images after laminectomy with the thick white arrow showing the thecal sac and the thin dark arrow showing the anterior hypervascular masses. 
improvement seen in 3-7 days of initiation. ${ }^{11}$ Doses used vary from 1,000 to 3,000 cGy. A relative high risk of recurrence is main disadvantage reported to be around $19-37 \% .^{12}$ It can be used as primary treatment or along with other modalities. Hydroxyurea has also been used as an effective treatment modality for EMH..$^{13}$ This ribonucleotide reductase enzyme inhibitor reduces the globin chain imbalance through stimulation of fetal hemoglobin synthesis, thereby ameliorating ineffective erythropoiesis, which is the primary stimulus for EMH development progression. However it cannot be used as a single modality but as a part of a multimodality treatment.

Laminectomy is the treatment of choice in acute presentation which require immediate decompression like in this case report where cauda equina syndrome mandated immediate decompression or when other modalities fail. ${ }^{14}$ It has the advantages of immediate relief of cord compression and also histological diagnosis. Disadvantages include risk of bleeding associated with the high vascularity of the masses and the risk of operating on anaemic patient who are predisposed excision in case of diffuse involvement, instability, kyphosis associated with multilevel laminectomy. In spite of these treatment recommendations the management should be based on every patient profile and use of multimodal approach in case of inadequate response to one line of treatment.

\section{Conclusion}

This case is a rare case of sacral canal compression due to EMH leading to cauda equina syndrome.

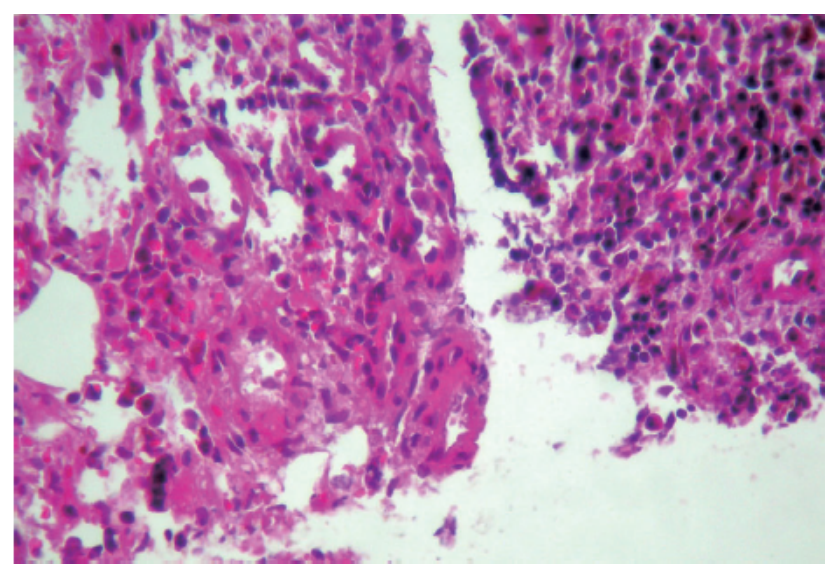

Fig. 5. Histological examination showing hyperplastic bone marrow with many deposits of foamy histiocytes within an erythroid hyperplasia.
Spinal cord compression by EMH during thalassemia is uncommon but can induce severe sequelae if the diagnosis is not rapidly obtained. Management of these patients should be individualized and one has to be vigilant for adequate response to one form of treatment or use a multimodal approach. Laminectomy in cases with acute presentation or progressive neurological deficits is a suitable option to prevent further neurological deficit.

\section{References}

1. Zamanizadeh B, Eghbali SS, Taghipour M, Haghnegahdar A, Zare Z. Spinal cord compression secondary to extramedullary hematopoiesis: Case report and summary. Neurosurg Q 16: 144-146, 2006.

2. Gatto I, Terrana V, Biondi L: [Compression of the spinal cord due to proliferation of bone marrow in epidural space in a splenectomized person with Cooley's disease.] Haematologica 38:61-75, 1954 (Ital).

3. Salehi SA, Koski T, Ondra SL. Spinal cord compression in beta thalassemia: case report and review of the literature. Spinal Cord 42: 117-123, 2004.

4. Ginzel AW, Kransdorf MJ, Peterson JJ, Garner HW, Murphey MD: Mass-like extramedullary hematopoiesis: imaging features. Skeletal Radiol 41:911-916, 2012.

5. Guermazi A, Miaux Y, Chiras J. Imaging of spinal cord compression due to thoracic extramedullary haematopoiesis in myelofibrosis. Neuroradiology 1997; 39: 733-6.

6. Da Costa JL, Loh YS, Hanam E: Extramedullary hemopoiesis with multiple tumor-simulating mediastinal masses in hemoglobin E-thalassemia disease. Chest 65:210-212, 1974.

7. Heffez DS, Sawaya R, Udvarhelyi GB, Mann R. Spinal epidural extramedullary hematopoisesis with cord compression in a patient with refractory sideroblastic anemia. J Neurosurg 57: 399-406, 1982.

8. Cook G, Sharp RA. Spinal cord compression due to extramedullary haemopoiesis in myelofibrosis. J Clin Pathol 1994; 47: 464-5.

9. Tsitouridis J, Stamos S, Hassapopoulou E, Tsitouridis K, Nikolopoulos P. Extramedullary paraspinal hematopoiesis in thalassemia: $\mathrm{CT}$ and MRI evaluation. Eur J Radiol. 1999;30:33-38. doi: 
10.1016/S0720-048X(98)00101-6.

10. Cardia E, Toscano S, La Rosa G, Zaccone C, d'Avella D, Tomasello F. Spinal cord compression in homozygous beta thalassemia intermedia. Pediatr Neurosurg. 1994;20:186-189. doi: 10.1159/ 000120785.

11. Malik M, Pillai LS, Gogia N, Puri T, Mahapatra $\mathrm{M}$, Sharma DN, et al: Paraplegia due to extramedullary hematopoiesis in thalassemia treated successfully with radiation therapy. Haematologica 92:e28-e30, 2007.

12. Papavasiliou C, Sandilos P: Effect of radiotherapy on symptoms due to heterotopic marrow in betathalassaemia. Lancet 1:13-14, 1987.

13. Cario H, Wegener M, Debatin KM, Kohne E: Treatment with hydroxyurea in thalassemia intermedia with paravertebral pseudotumors of extramedullary hematopoiesis. Ann Hematol 81:478-482, 2002.

14. Jackson DV, Jr, Randall ME, Richards F., 2nd
Spinal cord compression due to extramedullary hematopoiesis in thalassemia: long-term follow-up after radiotherapy. Surg Neurol. 1988;29:388-392.

\section{Disclosures \& COI}

The authors report no disclosures or conflicts of interest.

\section{Corresponding Author}

Shardul Soman, 4th floor, Government Spine Institute and Paraplegia Hospital, Asarwa, Ahmedabad, India.somanshardul@gmail.com.

Published 30 June 2016.

This manuscript is generously published free of charge by ISASS, the International Society for the Advancement of Spine Surgery. Copyright @ 2016 ISASS. To see more or order reprints or permissions, see http://ijssurgery.com. 